\title{
PEMETAAN KEBUTUHAN SISTEM INFORMASI MANAJEMEN TERPADU SINODE GEREJA-GEREJA KRISTEN JAWA
}

\author{
Umi Proboyekti1*, Budi Susanto ${ }^{2}$, Gloria Virginia ${ }^{3}$, Restyandito ${ }^{4}$ \\ 1,2,3,4 Fakultas Teknologi Informasi, Universitas Kristen Duta Wacana \\ Jalan Dr. Wahidin Sudirohusodo 5-25 Yogyakarta \\ Email: ${ }^{1}$ othie@si.ukdw.ac.id; 2-budsus@ti.ukdw.ac.id; ${ }^{3}$ virginia@ti.ukdw.ac.id; ${ }^{4}$ dito@ti.ukdw.ac.id \\ * Penulis korespondensi
}

\begin{abstract}
Abstrak: Pemetaan kebutuhan untuk mengembangkan SIM terpadu GKJ adalah proses lanjutan setelah penyusunan perencanaan strategis. Pemetaan ini bertujuan untuk mendapatkan profil gereja. Profil ini terdiri dari sumber daya manusia, infrastruktur TI, teknologi informasi yang diterapkan. Teknik pengumpulan data yang digunakan adalah FGD dan kuesioner. Kuisioner online mendapatkan sedikit respon karena kesenjangan teknologi dan tidak dikenal baik. Kuesioner tercetak kemudian dikirim untuk menjangkau sebagian besar gereja. Sementara gereja-gereja menyelesaikan dan mengirim kembali kuesioner, tim memutuskan untuk mulai merancang sistem informasi untuk Sinode dengan menjadwalkan FGD untuk pengumpulan kebutuhan. Tim belajar bahwa karakteristik organisasi memainkan peran penting dalam mengembangkan SIM terpadu.
\end{abstract}

Kata kunci: Gereja-gereja kristen jawa; SIM; FGD; kuesioner.

\begin{abstract}
Requirement mapping for developing integrated MIS for Javanese Christian churches is the next step after composing the strategic planning. The mapping is aimed to get the profile of churches. The profile comprises human resources, supported infrastructure for IT, applied information technology. Data elicitation technique used was FGD and questionnaire. The online questionnaire had low responses due to the technology gap and unfamiliarity. Paper based questionnaire was sent to reach most of the churches. While the churches completing and sending back the questionnaires, the team decided to start working on the information system for Synod by scheduling a FGD for requirement elicitation. The team learned that the characteristic of the organization played a significant role in developing the integrated MIS.
\end{abstract}

Keywords: Javanese christian churches; MIS; FGD; questionnaire.

\section{PENDAHULUAN}

Dalam usaha mengembangkan sistem informasi manajemen terpadu, identifikasi kebutuhan fungsional dan non-fungsional sistem diperlukan. Tahapan awal ini dilakukan agar sistem informasi manajemen terpadu (SIMT) yang akan dibangun memenuhi dan sesuai dengan kebutuhan pengguna dan pemangku kepentingan. Pemetaan kebutuhan sistem informasi terpadu Sinode Gereja-gereja Kristen Jawa (GKJ) merupakan kegiatan idenfikasi kebutuhan pengguna.

Tujuan dari program pengabdian masyarakat adalah menyusun daftar kebutuhan pengguna SIMT Sinode GKJ. Untuk mencapai tujuan, kegiatan yang dilakukan adalah pemetaan kebutuhan pengguna. Kegiatan ini merupakan tindak lanjut dari program sebelumnya, yaitu penyusunan Rencana Induk Pengembangan Sistem informasi mana- jemen terpadu (RIP SIMT) Sinode GKJ. Tim pemetaan adalah tim yang mengerjakan RIP SIMT. SIM telah menjadi kebutuhan bagi gereja-gereja. Sebagian gereja di Sinode GKJ telah memanfaatkan sistem informasi manajemen untuk mendukung pelayanan, sistem-sistem itu berdiri sendiri, tidak terkait dengan gereja lain atau klasis.

Pemetaan kebutuhan yang akan dilakukan menggunakan teknik FGD dan kuesioner. Dua teknik yang umum dilakukan. Jumlah pihak yang menjadi subjek pemetaan menjadi satu tantangan bagi Tim FTI UKDW dan Sinode GKJ. Keragaman kondisi atau profil pengguna dan lokasi yang tersebar di pulau Jawa menjadi tantangan berikutnya. Fokus dari penulis dalam tulisan ini adalah masalah yang dihadapi dan keterkaitan masalah dan karakteristik organisasi.

Untuk menjelaskan kegiatan pemetaan, maka tulisan ini disusun sebagai berikut: pengembangan 
RIP SIMPT menjadi penjelasan awal dari kegiatan ini karena kegiatan pemetaan merupakan kelanjutan dari program pengembangan RIP SIMPT. Pembahasan dilanjutkan dengan penjabaran tata kelola Sinode GKJ. Bahasan berikut penjelasan metode pelaksanaan dan ditutup dengan penjelasan hasil dan pembahasan hasil. Penekanan pembahasan hasil adalah masalah dalam proses memetakan kebutuhan

\section{Pengembangan Rencana Induk Pengembang- an SIMPT}

Tim Pengabdian dari Fakultas Teknologi Informasi (FTI), Universitas Kristen Duta Wacana (UKDW) telah melakukan pelayanan dan pengabdian Sinode GKJ untuk membangun Rencana Induk Pengembangan Sistem Informasi Manajemen Terpadu (RIP SIMT) karena masalah utama yang dihadapi Sinode GKJ adalah ketersediaan sumber daya manusia dengan kompetensi yang sesuai dan dukungan dana untuk mewujudkan RIP SIMT(Virginia, Susanto and Proboyekti, 2018).

Tim gabungan dari FTI UKDW dan Sinode GKJ dibentuk untuk penyusunan RIP SIMT. Tim gabungan sepakat menggunakan pendekatan Cassidy dalam menyusun rencana strategis (Cassidy, 2006) dan Appreciative Inquiry (AI) (Cooperrider, Whitney and Stavros, 2008). Mengikuti pemikiran dari Cassidy pembangunan suatu Rencana Induk Pengembangan (RIP) atau Rencana Strategis SIM dapat dilakukan dalam empat tahap utama, yaitu: Tahap Visi, Tahap Analisis, Tahap Pendefinisian Arah, dan Tahap Rekomendasi (Cassidy, 2006). Tahap-tahap itu digabungkan dalam pendekatan AI yaitu: Discovery, Dream, Design dan Destiny (Cooperrider, Whitney and Stavros, 2008). Tiap tahap dalam kedua pendekatan itu sejalan sehingga dapat digabungkan:

1. Discovery digabungkan dengan tahap visi dan tahap analisis

2. Dream digabungkan dengan sebagian tahap pendefinisian arah.

3. Design digabungkan dengan sebagian tahap pendefinisian arah

4. Destiny digabungkan dengan tahap rekomendasi (Tim Penyusun SIMT Sinode GKJ, 2018).

Pendekatan tersebut memberikan kebebasan kepada komunitas gereja untuk menentukan kapasitas yang akan diproses selanjutnya (Susanto, Proboyekti and Virginia, 2018). Pendekatan membimbing tim untuk mengetahui kebutuhan dan harapan dari seluruh pemangku kepentingan yang berinteraksi dengan SIMT atau merasakan dampaknya. Penyusunan rencana strategis pengembangan SIMT mengikuti konsep dasar peren- canaan: (a) identifikasi kondisi terkini dari SIMT Sinode GKJ (b) identifikasi posisi pencapaian SIMT ke depannya; dan (c) mengidentifikasi strategi penerapan untuk meraih capaian yang diharapkan (Restyandito; et al., 2018).

Tahapan identifikasi kondisi terkini dari SIMT Sinode GKJ merupakan tahapan yang banyak melibatkan personel-personel dari pengurus Sinode GKJ dan wakil dari beberapa klasis. Metode yang digunakan untuk mendapatkan data adalah Focus Group Discussion (FGD) dan wawancara. FGD digunakan untuk mendapatkan informasi tentang aliran informasi dan distribusi informasi di lingkungan Sinode GKJ (Proboyekti, Susanto and Virginia, 2018). Hasil identifikasi kondisi terkini tersebut menjadi materi dalam tahapan berikutnya yang bersifat analisis dan dilakukan oleh Tim FTI UKDW dan Sinode GKJ.

Aliran informasi di lingkungan Sinode GKJ dijabarkan dalam beberapa tabel untuk memperlihatkan informasi yang menjadi input atau output sistem, pengguna informasi dan pihak yang bertanggung jawab untuk menyajikan informasi tersebut. Contoh dari jenis informasi, pengguna dan penanggung jawab informasi.

menjabarkan contoh jenis informasi yang terdistribusi sebagai input atau output. Informasi yang dijadikan contoh merupakan informasi tentang jemaat, baik terkait profil atau aktifitasnya.

Tabel 1. Contoh Jenis dan Jumlah Kebutuhan Informasi (Tim Penyusun SIMT Sinode GKJ, 2018)

\begin{tabular}{clccc}
\hline No & Informasi & Jumlah I/O & Input & Output \\
\hline 1 & Biodata Jemaat & 15 & 5 & 10 \\
2 & Pernikahan & 8 & 2 & 6 \\
3 & Kelahiran & 3 & 2 & 1 \\
4 & Baptis/Sidi & 5 & 2 & 3 \\
5 & Kematian & 7 & 3 & 4 \\
6 & Atestasi Masuk & 8 & 2 & 6 \\
7 & Atestasi Keluar & 8 & 2 & 6 \\
8 & Aktifitas Bergereja & 10 & 3 & 7 \\
9 & Komisi & 4 & 1 & 3 \\
10 & Komunitas & 7 & 1 & 6 \\
11 & Kehadiran & 7 & 2 & 5 \\
12 & Statistik Laporan & 8 & 3 & 5 \\
& Kehadiran & & & \\
\hline
\end{tabular}

Contoh informasi pengguna dan kebutuhan informasi dijabarkan dalam Tabel 2. Jemaat mempunyai kebutuhan informasi terbatas dibanding tanggung jawabnya sebagai penyedia informasi pada Tabel 3. Sementara pengguna yang mempunyai banyak kebutuhan informasi dan tanggung jawab informasi di antaranya adalah BPH Sinode dan Kantor Sinode.

Hasil akhir dari tahapan penyusunan adalah rekomendasi sistem informasi manajemen dan teknologi informasi. Rekomendasi arsitektur SIMT 
yang diberikan adalah infrastruktur layanan perkantoran dan kolaborasi sebagai lapisan pendukung fungsional perlu dibangun. Adapun sistem informasi manajemen yang perlu ada adalah: Sistem Manajemen Surat Masuk dan Keluar, Sistem Manajemen Dokumen dan arsip; Sistem Manajemen informasi Personal; Sistem Penjadwalan; Sistem kolaborasi; Sistem Manajemen Konten, dan Sistem Kanal Komunikasi (Susanto, Proboyekti and Virginia, 2018).

Tabel 2. Contoh Pengguna dan Jumlah Kebutuhan Informasi (Tim Penyusun SIMT Sinode GKJ, 2018)

\begin{tabular}{clc}
\hline No & Tipe Pengguna & Jumlah kebutuhan \\
\hline 1 & Gereja & 10 \\
2 & BPH Sinode & 26 \\
3 & Kantor Sinode & 10 \\
4 & Bapelsin Bid. Visitasi & 13 \\
5 & Bawasin Bid. Visitasi & 2 \\
6 & Klasis & 3 \\
7 & Jemaat & 2 \\
\hline
\end{tabular}

Tabel 3. Contoh Pengguna dan Jumlah Tanggung Jawab Informasi (Tim Penyusun SIMT Sinode GKJ, 2018)

\begin{tabular}{clc}
\hline No & Tipe Pengguna & Jumlah informasi \\
\hline 1 & Gereja & 13 \\
2 & Kantor Sinode & 27 \\
3 & Jemaat & 18 \\
4 & BPH Sinode & 18 \\
5 & Klasis & 8 \\
\hline
\end{tabular}

Berdasarkan rencana operasional September 2018-Desember 2019 (Fakultas Teknologi Informasi UKDW, 2018) maka kegiatan pengembangan SIMT adalah sebagai berikut:

1. Setup dan Pengembangan Office Support Layer;

2. Penyediaan layanan web hosting bagi Gerejagereja Kristen Jawa

3. Penataan layanan email bagi Sinode, Klasis dan Gereja.

4. Perancangan dan pengembangan Manajemen Konten berbasis Web

Kegiatan perancangan dan pengembangan Manajemen Konten berbasis Web meliputi sub kegiatan-kegiatan berikut:

1. memetakan seluruh kebutuhan informasi yang harus dipublikasikan.

2. merancang kebutuhan resource, termasuk waktu, SDM, dan dana.

3. merancang arsitektur informasi dan antarmuka pengguna

4. merancang arsitektur aplikasinya dengan memperhatikan kebutuhan akses pada aplikasi mobile

5. memasang Wordpress, theme, dan plugin

6. mengembangkan aplikasi berbasis Android dan iPhone untuk Konten Web Sinode GKJ (Fakultas Teknologi Informasi UKDW, 2018).
Dengan demikian memetakan seluruh kebutuhan informasi merupakan kegiatan awal yang akan mendasari kegiatan-kegiatan pengembangan SIMT. Pemetaan dilakukan dengan mengumpulkan data tentang profil tiap gereja, kondisi teknologi informasi yang digunakan dan pemanfaatannya serta sumber daya manusia yang menggunakan. Pengumpulan dilakukan melalui kuesioner. Selain itu, Focus Group Discussion terapkan untuk mendapatkan kebutuhan informasi. Dua teknik tersebut merupakan teknik yang diterapkan dalam pemetaan kebutuhan.

\section{Penjelasan Organisasi SINODE GKJ}

Sinode GKJ terdiri dari 32 Klasis dengan 332 Gereja Dewasa dan 554 Pos Pelayanan (Restyandito; et al., 2018) tersebar di seluruh pulau Jawa. Sifat keterkaitan antar gereja-gereja adalah persekutuan, berdasarkan kesepakatan bersama, dan kesepakatan itu dibuat bersama di dalam sidang. Ada dua jenis sidang, yaitu klasis dan sinode. Klasis merupakan persekutuan beberapa gereja dalam area daerah yang berdekatan, sementara sinode adalah persekutuan semua klasis. Di setiap sidang dibicarakan dan diputuskan bersama keputusankeputusan yang diberlakukan di semua gereja. Sidang Sinode GKJ yang diadakan 4 tahun sekali, sementara sidang klasis setiap 1 atau 2 tahun tergantung kesepakatan gereja-gereja dalam klasis tersebut. Peserta sidang sinode adalah utusan klasis, semua klasis. Peserta sidang klasis adalah utusan gereja yang merupakan anggota klasis. Setiap kesepakatan yang dihasilkan dari sidang, baik klasis maupun sinode, bersifat mengikat secara moral dan tidak ada konsekuensi bagi yang tidak atau belum melakukan kesepakatan.

Setiap gereja memiliki otonomi untuk menentukan dan mengatur dirinya sendiri. Persekutuan antar gereja-gereja ini merupakan tatanan kehidupan bersama ini memberi ruang kemandirian gereja dan sekaligus mewujudkan kebersamaan. Kebersamaan dalam klasis dan sinode untuk mewujudkan karya Allah yang hidup berdasarkan pada Alkitab, Pokok Pokok Ajaran GKJ, serta Tata Gereja dan Tata Laksana GKJ yang berwatak pastoral transformative (Sinode GKJ, 2018). Sekalipun memiliki otonomi penuh, gereja membutuhkan sinode dalam sisi hukum dan ajaran. Perlindungan yang diberikan oleh Sinode adalah ajaran dan payung hukum atas nama Sinode GKJ. Sinode bertanggung jawab memastikan bahwa ajaran yang diberikan di semua Gereja Kristen Jawa sesuai dengan ajaran yang telah disepakati (Sinode GKJ, 2019).

Gereja-gereja Kristen Jawa tersebar di seluruh Pulau Jawa, baik di kota besar, kota kecil, dan pedesaan. Otonomi membuat setiap gereja menge- 
lola dirinya sendiri. Sebagian gereja memiliki kemapanan tinggi sehingga dapat menerapkan teknologi informasi untuk mendukung operasional dan pelayanan. Sebagian lagi memiliki kemampanan sedang dan rendah sehingga fasilitas terbatas bahkan sampai pada taraf membutuhkan bantuan. Bantuan diperoleh dari gereja-gereja yang lebih mapan melalui sinode yang menentukan aturan penyaluran bantuan (Sinode GKJ, 2018).

Selain mekanisme bantuan, mekanisme lain seperti penyediaan materi pelayanan, hasil sidang, dan distribusi informasi dari dan ke klasis menjadi hal yang membutuhkan waktu, tenaga dan biaya untuk menjangkau semua gereja. Teknologi informasi kemudian dirasa perlu untuk dihadirkan guna mendukung pelayanan sinode dan klasis. Karena itu visi yang mendasari pengembangan Sistem Informasi Manajemen Terpadu (SIMT): SIMT gereja presbiterial pendukung pelayanan integratif berdasarkan kecakapan berteologi secara kontekstual.

Untuk mewujudkan visi pengembangan dan penerapan SIMT Sinode GKJ tersebut, didefinisikan beberapa misi:

1. Memiliki pusat data yang dapat diandalkan dengan dukungan infrastruktur yang memadai;

2. Menyediakan layanan informasi yang mendukung analisis dan pengambilan keputusan yang integratif dan kontekstual;

3. Menerapkan teknologi dan aplikasi yang mendukung akses luas terhadap informasi;

4. Membangun jejaring dalam penerapan dan pengembangan SIMT yang profesional;

5. Mengimplementasikan metodologi pengembangan SIMT yang responsif dan integratif terhadap kebutuhan;

6. Menyiapkan sumber daya manusia yang memiliki kapasitas untuk memanfaatkan SIMT secara maksimal dan bertanggung jawab;

7. Membangun budaya yang ramah dan cerdas terhadap teknologi dan pemanfaatannya (Tim Penyusun SIMT Sinode GKJ, 2018).

Pencapaian visi didukung oleh faktor sumber daya manusia, infrastruktur dan teknologi yang diterapkan, metodologi yang diterapkan dan budaya yang mendukung. Dari semua faktor ini, faktor manusia menjadi faktor penentu. Karena itu dalam tahapan pertama pengembangan SIMT yaitu pemetaan kebutuhan, faktor sumber daya manusia terlibat banyak baik sebagai pelaku, maupun sebagai sumber informasi.

\section{METODE PELAKSANAAN}

Pemetaan dilakukan untuk mengawali pengembangan sistem informasi jemaat karena data jemaat merupakan kebutuhan dasar dari penge- lolaan gereja dan klasis. Pemetaan kebutuhan dilakukan dengan teknik focus group discussion (FGD). Jika FGD sebelumnya dilakukan untuk mendapatkan aliran informasi yang didistribusikan di lingkungan Sinode GKJ, maka dalam pemetaan kebutuhan, informasi yang diperlukan adalah profil gereja. Profil gereja meliputi sumber daya manusia, dan teknologi informasi dan infrastruktur yang dimiliki. Informasi profil nantinya akan direlasikan dengan kebutuhan fungsional dan non fungsional dari sistem. Fungsional terkait kemampuan dari sistem, sementara non fungsional terkait pendukung agar sistem berfungsi sesuai dengan semestinya.

Responden FGD dalam pemetaan juga merupakan FGD sebelumnya, yaitu wakil dari klasis. Wakil-wakil dipilih oleh tim dari Sinode GKJ yang memahami kondisi gereja-gereja. Pemilihan didasari oleh wakil yang dapat mewakili kondisi gereja yang beragam. Gereja yang mapan, gereja yang kurang mapan, gereja yang berfasilitas teknologi informasi terbatas, dan gereja yang telah memanfaatkan teknologi informasi. Dalam pertemuan FGD tersebut, tim dari Sinode GKJ menjadi moderator untuk menjelaskan tujuan dan mengajukan pertanyaan kepada para wakil klasis.

Dari FGD didapatkan beragam informasi terkait infrastruktur, fitur sistem, kemampuan sumber daya manusia dan informasi yang dibutuhkan. Contoh infrastruktur adalah koneksi internet yang terbatas. Kebutuhan akan koneksi internet merupakan kebutuhan non fungsional. Modifikasi sistem sesuai dengan kebutuhan gereja adalah contoh fitur sistem. Hal ini berelasi kuat dengan otonomi gereja untuk mengelola dirinya sendiri. Informasi jemaat yang perlu dilayani merupakan informasi yang diperlukan untuk dapat melayani tepat sasaran. Ini adalah kebutuhan informasi dari sistem. Kebutuhan-kebutuhan ini diperoleh selama FGD yang suasananya digambarkan di Gambar 1. Suasana FGD

Informasi dari FGD yang dihadiri oleh 11 wakil dari klasis ini dianggap tidak cukup untuk memberikan gambaran lengkap dari kondisi gerejagereja di Sinode yang beragam. Karena itu kuesioner disiapkan untuk menjangkau lebih banyak gereja dan klasis. Kuesioner disiapkan dalam format online dengan menggunakan Google Form. Penyebaran informasi pengisian kuesioner dan URL dari Google Form dilakukan melalui messenger application. Dalam praktiknya, hal yang efisien ternyata belum tentu efektif. Kuesioner online hanya diisi oleh kurang dari 40 gereja. Kuesioner kemudian dicetak dan dikirimkan melalui pos ke gereja-gereja dan klasis yang belum mengisi kuesioner.

Informasi dari FGD yang dihadiri oleh 11 wakil dari klasis ini dianggap tidak cukup untuk 
memberikan gambaran lengkap dari kondisi gerejagereja di Sinode yang beragam. Karena itu kuesioner disiapkan untuk menjangkau lebih banyak gereja dan klasis. Kuesioner disiapkan dalam format online dengan menggunakan Google Form. Penyebaran informasi pengisian kuesioner dan URL dari Google Form dilakukan melalui messenger application. Dalam praktiknya, hal yang efisien ternyata belum tentu efektif. Kuesioner online hanya diisi oleh kurang dari 40 gereja. Kuesioner kemudian dicetak dan dikirimkan melalui pos ke gereja-gereja dan klasis yang belum mengisi kuesioner.

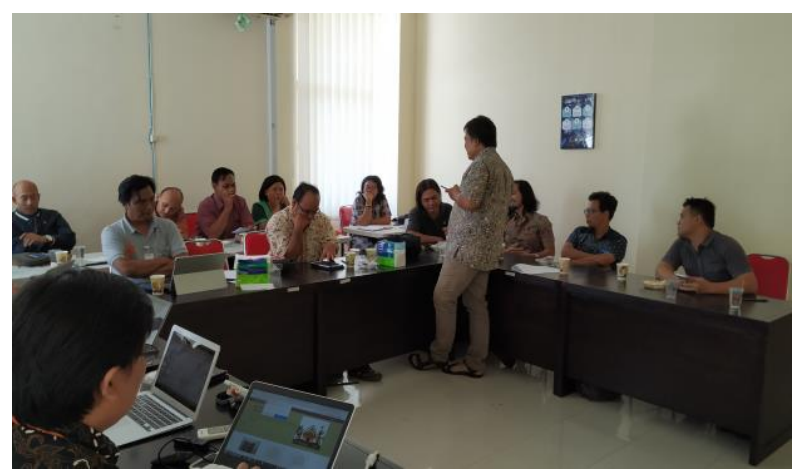

Gambar 1. Suasana FGD

\section{HASIL DAN PEMBAHASAN}

Program pemetaan kebutuhan yang menggunakan FGD dan kuesioner dapat dikatakan tidak memenuhi kebutuhan untuk menghasilkan dokumen hasil pemetaan. Kondisi ini kemudian didiskusikan tim gabungan secara internal untuk mengevaluasi teknik yang diterapkan. Dari diskusi didapatkan beberapa hal yang berkontribusi pada pengisian kuesioner yang minim:

1. Sumber daya manusia: Bagi sebagian besar kalangan gereja, kuesioner online tidak dikenal sehingga ada keengganan untuk mengisinya atau kepercayaan terhadap informasi yang disampaikan lewat internet masih rendah.

2. Otonomi gereja: pengisian kuesioner berdasarkan kerelaan untuk berbagi informasi tentang profil gereja. Namun demikian, setiap gereja punya keputusan sendiri mengisi.

3. Tata kelola sinode: RIP SIMT belum dibahas di sidang sinode, otomatis pengisian kuesioner yang disebarkan belum menjadi kesepakatan bersama. Sementara FGD untuk mendatangkan wakil dari semua klasis terkendala biaya yang terbatas.

4. Sosialisasi tentang RIP SIMT belum menyeluruh sehingga sebagian besar klasis dan gereja tidak mengetahui RIP SIMT dan proses terkaitnya.

Sementara FGD yang telah dilakukan belum berhasil mendatangkan wakil-wakil klasis yang dapat memberikan data yang Selain membahas halhal yang menjadi kendala dalam pemetaan kebutuhan. Tim juga melakukan curah pendapat alternative jalan keluar untuk mengatasi masalah pemetaan kebutuhan.

1. Tetap memberi waktu kepada gereja-gereja untuk mengisi dan mengirimkan kuesioner dalam bentuk tercetak

2. Mengerahkan mahasiswa S1 Teologia UKDW untuk mengunjungi gereja-gereja di daerahnya atau daerah yang dapat dijangkaunya. Kunjungan dimaksudkan untuk membantu gerejagereja tersebut mengisi kuesioner secara online. Dengan demikian gereja terbantu dan mahasiswa punya pengetahuan tambahan tentang kondisi gereja.

3. Mengarahkan proses selanjutnya ke pemetaan kebutuhan untuk sistem informasi yang mendukung operasional Sinode. Hal ini diperlukan untuk mendukung kerja badan-badan pelayanan di sinode yang membutuhkan dukungan untuk komunikasikan program kerja, pengawasan dan laporan pelaksanaan program.

Hasil diskusi tim gabungan memutuskan untuk melakukan alternative pertama dan ketiga dengan pertimbangan: kuesioner sudah tersebar dan sudah ada data yang terkumpul. Pengumpulan kuesioner hanya membutuhkan waktu untuk mendapatkan data yang lebih mewakili. Pengumpulan kuesioner didukung oleh aplikasi pesan elektronik Whatsapp. Pihak gereja mengirimkan kuesioner terisi dalam bentuk file foto ke kantor Sinode GKJ. Hingga pertengahan Agustus 2019, tercatat 70 gereja dan klasis telah mengirimkan data mereka.

Sementara alternatif ketiga dipandang perlu untuk dilakukan agar tim dapat menghasilkan suatu sistem yang akan dirasakan manfaatnya dan kemudian dapat menjadi penguat bagi gereja-gereja untuk mendukung pengembangan SIMT. Pemetaan kebutuhan pada alternatif ketiga dianggap lebih sederhana karena subjek sumber informasi lebih mudah untuk dikumpulkan dan dilakukan pemetaan. Sebagai tindak lanjut nyata dari alternatif ketiga, tim Sinode GKJ telah menetapkan waktu pertemuan untuk FGD di awal bulan Agustus 2019. Peserta FGD adalah personil dari Badan pelayanan sinode yang dianggap tepat untuk menjadi sumber informasi.

\section{KESIMPULAN}

Sistem informasi manajemen jemaat, Tim FTI UKDW memperoleh pengalaman bekerja dengan organisasi keagamaan dalam hal ini Sinode GKJ. Tata kelola Sinode GKJ yang berbasis kesepakatan dan persekutuan antar gereja-gereja yang otonom membutuhkan banyak usaha untuk mengkomunikasikan dan melibatkan personil-personil yang tepat. 
Fleksibilitas dalam menjalani tahapan dibutuhkan untuk dapat tetap mewujudkan SIMT Sinode GKJ. Dengan demikian, alternative prioritas dan kegiatan perlu dipikirkan dan disiapkan agar progress pengembangan SIMT tetap ada.

Sumber daya manusia berperan penting dalam pengembangan SIMT. Pengetahuan personil-personil di gereja tentang penggunaan teknologi informasi untuk berkomunikasi dan mendistribusikan infomasi perlu ditingkatkan. Dengan demikian semakin banyak pihak-pihak yang merasakan manfaat teknologi informasi dan paham pentingnya teknologi informasi untuk pengelolaan gereja.

\section{UCAPAN TERIMA KASIH}

Terima kasih ditujukan kepada BPH Sinode GKJ yang mempercayakan proses mengembangkan sistem informasi manajemen terintegrasi dari pembangunan rencana strategis hingga teknis pengembangan kepada Fakultas Teknologi Informasi UKDW. Sekalipun pengembangan masih terus berlanjut, pengalaman melakukan pemetaan kebutuhan sistem merupakan kesempatan yang berharga dan menjadi pengetahuan yang memperkaya pengajaran dan pendidikan.

Terima kasih kepada LPPM UKDW yang mendukung dengan dana untuk Tim dapat melakukan kegiatan dengan lancar.

\section{DAFTAR PUSTAKA}

Cassidy, A. (2006) A Practical Guide to Information Systems Strategic Planning, A Practical Guide to Information Systems Strategic Planning. Boca Raton: Auerbach Publications. doi: 10.1201/9781420048605.
Cooperrider, D. L., Whitney, D. and Stavros, J. M. (2008) Appreciative Inquiry Handbook for Leaders of Change. 2nd edn. San Francisco, California: Berret-Koehler Publishers.

Fakultas Teknologi Informasi UKDW (2018) Rencana Operasional Pengembangan SIM Terpadu. Yogyakarta.

Proboyekti, U., Susanto, B. and Virginia, G. (2018) 'Focus Group Discussion (FGD) dalam Penyusunan Rencana Strategis Lembaga Gereja', in Seminar Nasional Hasil Pengabdian kepada Masyarakat. Jakarta: LPPM UKRIDA, pp. 153-160.

Restyandito; et al. (2018) 'Perancangan Rencana Induk Pengembangan Sistem Informasi Manajemen Terpadu', in Seminar Nasional Hasil Pengabdian kepada Masyarakat. Jakarta: LPPM UKRIDA, pp. 188-195.

Sinode GKJ (2018) Tata Gereja dan Tata Laksana GKJ. Salatiga, Jawa Tengah: Sinode GKJ.

Sinode GKJ (2019) Pokok-Pokok Ajaran GKJ. Salatiga, Jawa Tengah: Sinode.

Susanto, B., Proboyekti, U. and Virginia, G. (2018) 'Rekomendasi Pengembangan Sistem Informasi Terpadu Sinode GKJ', in Seminar Nasional Hasil Pengabdian kepada Masyarakat. Jakarta: LPPM UKRIDA, pp. 464-470.

Tim Penyusun SIMT Sinode GKJ (2018) Dokumen Rencana Induk Pengembangan Sistem Informasi Manajemen Terpadu di Lingkungan Sinode GKJ. Salatiga, Jawa Tengah.

Virginia, G., Susanto, B. and Proboyekti, U. (2018) 'Logical Framework Analysis dan Appreciative Inquiry dalam Perencanaan Strategis Sistem Informasi Manajemen Organisasi', in Seminar Nasional Hasil Pengabdian kepada Masyarakat. Jakarta: LPPM UKRIDA, pp. 265-271 